\title{
Identification and Characterization of Arsenite Methyltransferase from an Archaeon, Methanosarcina acetivorans C2A
}

\author{
Pei-Pei Wang, ${ }^{\dagger,}$ Guo-Xin Sun, ${ }^{\dagger} \dagger$ and Yong-Guan $\mathrm{Zhu}^{*}, \dagger, \S$ \\ ${ }^{\dagger}$ State Key Lab of Urban and Regional Ecology, Research Center for Eco-Environmental Sciences, Chinese Academy of Sciences, \\ Beijing 100085, People's Republic of China \\ ${ }^{\ddagger}$ University of Chinese Academy of Sciences, Beijing 100049, People's Republic of China \\ ${ }^{\S}$ Key Lab of Urban Environment and Health, Institute of Urban Environment, Chinese Academy of Sciences, Xiamen 361021, \\ People's Republic of China
}

\section{Supporting Information}

ABSTRACT: Arsenic is a ubiquitous toxic contaminant in the environment. The methylation of arsenic can affect its toxicity and is primarily mediated by biological processes. Few studies have focused on the mechanism of arsenic methylation in archaea although archaea are widespread in the environment. Here, an arsenite $[$ As(III)] methyltransferase (ArsM) was identified and characterized from an archaeon Methanosarcina acetivorans C2A. Heterologous expression of MaarsM was shown to confer As(III) resistance to an arsenic-sensitive strain of $E$. coli through arsenic methylation and subsequent volatilization. Purified MaArsM protein was further identified the function in catalyzing the formation of various methylated products from As(III) in vitro. Methylation of As(III) by MaArsM is highly dependent on the characteristics of the thiol cofactors used, with some of them (coenzyme M, homocysteine, and dithiothreitol) more efficient than GSH. Site-directed mutagenesis demonstrated that three conserved cysteine (Cys) residues (Cys62, Cys150, and Cys200) in MaArsM were necessary for As(III) methylation, of which only Cys150 and Cys200 were required for the methylation of monomethylarsenic. These results present a molecular pathway for arsenic methylation in archaea and provide some insight into the role of archaea in As biogeochemistry.

\section{INTRODUCTION}

Arsenic (As) has received considerable attention worldwide, since As pollution in soil or water is widespread and often leads to a multitude of toxic effects. Arsenic methylation is a ubiquitous phenomenon in the environment and is primarily mediated by biological actions. Arsenic methylation is acknowledged to be a significant mechanism involving As detoxification since the pentavalent methylated As are less toxic than the inorganic As. Moreover, volatilized As as the final product of methylation has been suggested to contribute to global As cycling. ${ }^{1,2}$ One methylcobalamin-dependent methylation of As, which does not require an enzyme, has been reported in methanoarchaea. ${ }^{3,4}$ Whether there exists an enzymatic pathway for As methylation in archaea is still unclear. Arsenic methyltransferase which is responsible for As methylation, has been identified and characterized in members of several kingdoms, from bacteria to human, ${ }^{5-8}$ but it has yet to be conclusively identified in the archaea.

The archaea domain represents a third line of evolutionary descent, separate from bacteria and eukarya. ${ }^{9}$ These prokaryotes not only predominate in separate niches characterized by extreme temperatures, $\mathrm{pH}$, salinity, or anaerobiosis, ${ }^{10,11}$

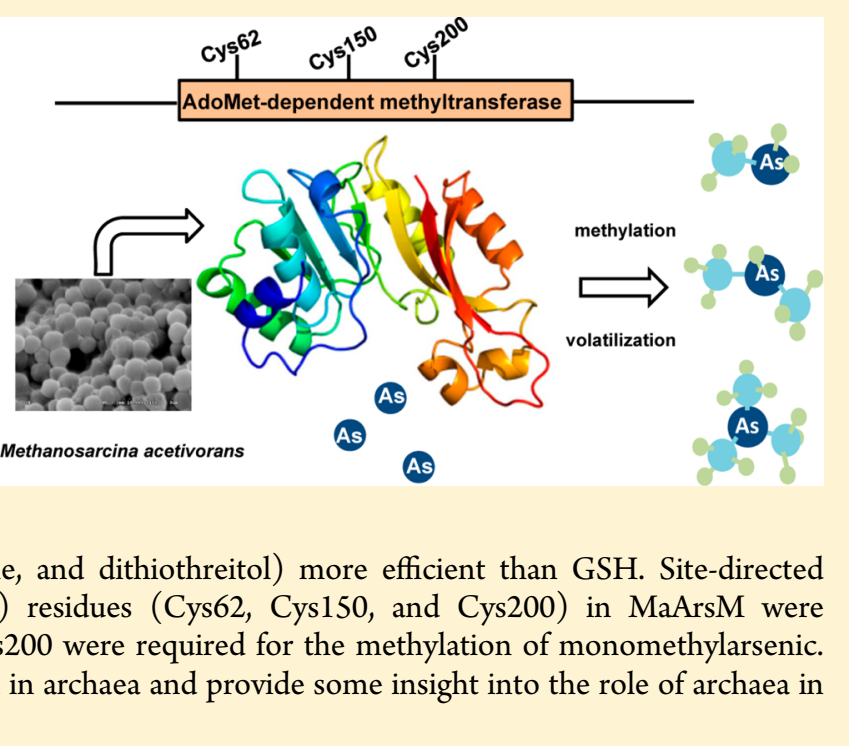

including hot springs, hydrothermal vents, salt lakes, soda lakes, sewage digesters, and the rumen, but also exhibit a wide distribution in common habitats, ${ }^{12,13}$ such as ocean or lake waters, soil etc. Despite the abundance and ubiquity in the environment, the archaea have not been studied as much as bacteria, especially on the As transformation in the environment.

Archaea can thrive in various anaerobic environments. Anaerobic environments, e.g., sediments and wetlands, provide an excellent setting to study microbe-arsenic interactions, ${ }^{14,15}$ since they often act as the sinks or secondary sources of As due to natural and anthropogenic activities. ${ }^{16,17}$ Generally, arsenic methylation is preferred under anaerobic conditions. ${ }^{1,18}$ For example, arsenic volatilization has been observed in many paddy soils or wetlands. ${ }^{19-23}$ Methylation and volatilization of metal(loid)s have been regarded as an inherent feature of

Received: August 7, 2014

Revised: October 3, 2014

Accepted: October 8, 2014

Published: October 8, 2014 
methanoarchaea, ${ }^{24,25}$ though the enzymatic mechanism of As methylation by archaea remains unknown.

In this study, we focused on the molecular mechanism of As methylation by a methanoarchaea. Methanosarcina acetivorans C2A was chosen as a model organism because of its available genomic information and the physiological, metabolic and environmental diversity. ${ }^{26}$ Our main objectives were (1) to identity As methylation and the involved enzyme in $M$. acetivorans $\mathrm{C} 2 \mathrm{~A},(2)$ to provide insight into the molecular mechanism of As methylation in archaea, and (3) to elucidate some characteristics of As(III) methyltransferase from archaea.

\section{MATERIALS AND METHODS}

Organisms and Cultivations. M. acetivorans $\mathrm{C} 2 \mathrm{~A}$ was purchased from American Type Culture Collection (ATCC) and anaerobically grown in ATCC Medium 1355 at $37^{\circ} \mathrm{C}$ in the dark. Media were boiled and cooled to room temperature under an atmosphere of $\mathrm{N}_{2}$ gas (purity $\geq 99.999 \%$ ). The media were dispensed into acid-cleaned serum bottles, sealed with butyl rubber stoppers and covered with aluminum foil, autoclaved at $121{ }^{\circ} \mathrm{C}$ for $20 \mathrm{~min}$. The headspace of serum bottles were exchanged by the filtered gas mixture $\left(80 \% \mathrm{H}_{2}\right.$ $20 \% \mathrm{CO}_{2}$ ) before inoculation.

E. coli were grown at $37{ }^{\circ} \mathrm{C}$ in $\mathrm{LB}$ media. Strain DH5 $\alpha$ (Promega) was used for plasmid replication. Strain AW3110(DE3) [ $\triangle$ arsRBC; ArsR-repressor; ArsB-As(III) efflux pump; $\operatorname{Ars} \mathrm{C}-\mathrm{As}(\mathrm{V})$ reductase] was used for the functional verification of arsM gene. Strain BL21(DE3) was used for protein purification.

Chemicals. Arsenicals were bought from J\&K Chemical Ltd. The thiol compounds in Supporting Information (SI) Table S1 and S-adenosyl-L-methionine (SAM) were bought from Sigma. All reagents are analytical grade or better.

Arsenic Methylation by M. acetivorans C2A. With $2 \%$ (v/v) inoculum, $M$. acetivorans C2A was inoculated into the medium supplemented by sodium arsenite $[\mathrm{As}(\mathrm{III})]$ or sodium arsenate $[\mathrm{As}(\mathrm{V})]$ to a concentration of 5 or $10 \mu \mathrm{M}$. After a growth of 20 days, the cultures were centrifuged at 8000 r.p.m. The supernatants were filtrated by $0.45 \mu \mathrm{m}$ disposable filter, and oxidized by $10 \%(\mathrm{v} / \mathrm{v}) \mathrm{H}_{2} \mathrm{O}_{2}$ overnight, then kept at $4{ }^{\circ} \mathrm{C}$ until analysis.

Cloning of the ars $M$ Gene from $M$. acetivorans C2A and Gene Expression in E. coli. The putative arsM gene in $M$. acetivorans $\mathrm{C} 2 \mathrm{~A}$ and other ars $\mathrm{Ms}$ from different species were searched in NCBI database. The ars $M$ gene alignments were carried out on DNAMAN software (Lynnan Corp, PointeClaire, QC, Canada). Genomic DNA was isolated from $M$. acetivorans C2A by using Genomic-Tip 20/G and Buffer set (Qiagen). A $763 \mathrm{bp}$ fragment containing ATG start codon and excluding TGA stop codon was PCR amplified from the genome of $M$. acetivorans $\mathrm{C} 2 \mathrm{~A}$ by using the forward primer: $5^{\prime}$ CGGAATTCATGGATGCCGCTGAAAAAAA-3' (EcoRI restriction endonuclease site underlined) and the reverse primer: 5'-CCCTCGAGTACCCAGGCCTTTAATTTGA-3' (XhoI restriction endonuclease site underlined). PCR reaction (94 ${ }^{\circ} \mathrm{C}$ for $5 \mathrm{~min}, 94^{\circ} \mathrm{C}$ for $30 \mathrm{~s}, 58^{\circ} \mathrm{C}$ for $30 \mathrm{~s}, 72{ }^{\circ} \mathrm{C}$ for $1 \mathrm{~min}, 30$ cycles) was performed with LA Taq DNA polymerase (Takara Bio). The PCR product was cloned into PMD19T simple vector (Takara Bio) to create the plasmid PMD19T-arsM. Plasmids were extracted with a QIAPrep Spin Miniprep kit (Qiagen) and sequenced to obtain a positive cloning. After digested with EcoRI and XhoI, arsM fragment was again inserted into pET28a+ vector to create plasmid pET28a+arsM.
The His-tagged ArsM established was composed of 293 amino acid residues, with a predicted molecular mass of $31.56 \mathrm{kDa}$.

Plasmid pET28a+ or pET28a+ars $M$ was transformed into $E$. coli AW3110(DE3). Transformed cells were grown in LB medium containing $50 \mu \mathrm{g} \mathrm{mL}{ }^{-1}$ kanamycin overnight, then diluted 50-fold into fresh medium containing $50 \mu \mathrm{g} \mathrm{mL}^{-1}$ kanamycin, $0.3 \mathrm{mM}$ IPTG, and a series of concentrations of $\operatorname{As}(\mathrm{III})(10,20$, and $50 \mu \mathrm{M})$. After a growth of $20 \mathrm{~h}$, the culture was centrifuged at 8000 r.p.m. The supernatant was filtrated by $0.45 \mu \mathrm{m}$ disposable filters, oxidized by $10 \%$ (v/v) $\mathrm{H}_{2} \mathrm{O}_{2}$ overnight and analyzed As species.

E. coli AW3110 expressing pET28a+ or $\mathrm{pET} 28 \mathrm{a}+\operatorname{ars} M$ were inoculated into LB medium containing $50 \mu \mathrm{g} \mathrm{mL}^{-1}$ kanamycin and cultured overnight. Late exponential phase cells were diluted 100 -fold into fresh medium containing $50 \mu \mathrm{g} \mathrm{mL}$ kanamycin, $0.3 \mathrm{mM}$ IPTG and a series of concentrations of As(III) $(0,50$, and $100 \mu \mathrm{M})$. Cellular growths were monitored as absorbance at $600 \mathrm{~nm}$ via $\mathrm{UV}-$ vis spectrophotometer (New Century, Model T6) until the cultures reached stationary phase.

Arsenic Volatilization by E. coli AW3110 Expressing arsM. Volatile As produced by E. coli expressing ars $M$ was chem-trapped as described. ${ }^{21}$ E. coli AW3110 bearing pET28a + ars $M$ or $\mathrm{pET} 28 \mathrm{a}+$ were cultured in triangular flasks $[250 \mathrm{~mL}$ volume; $100 \mathrm{~mL} \mathrm{LB}$ medium with a series of concentrations of As(III)]. Every flask was capped with a T-junction stopper having a gas inlet and a gas outlet. The inlet was linked to a super silent adjustable air pump (ACO-9601; 2-W power), to pump filtered air at a gas flow rate of $40 \mathrm{~mL} \mathrm{~min}^{-1}$. The outlet of $\mathrm{T}$-junction stopper was connected to a trapping tube filled with $\mathrm{AgNO}_{3}$-impregnated silica gel beads. After a $48 \mathrm{~h}$ growth, the total As absorbed by the trapping tube was eluted by $1 \%$ $(\mathrm{v} / \mathrm{v}) \mathrm{HNO}_{3}(5 \mathrm{~mL})$ in a microwave digestion system (Mars II, CEM, U.S.A.). The eluted suspension was centrifuged at 3000 r.p.m. The supernatant was filtrated by $0.45 \mu \mathrm{m}$ disposable filter and analyzed the quantity and species of As by HPLC-ICP-MS.

Purification of ArsM Enzyme and As(III) Methylation by Purified Enzyme in Vitro. E. coli BL21(DE3) bearing pET28a+MaarsM was grown in LB medium $(200 \mathrm{~mL})$ to an A600 of $0.4-0.6$ when $0.3 \mathrm{mM}$ IPTG was supplemented to induce expression of MaArsM. After a $8 \mathrm{~h}$ growth at $19{ }^{\circ} \mathrm{C}, \mathrm{E}$. coli was harvested by centrifugation (8000 r.p.m.) at $4{ }^{\circ} \mathrm{C}$ for 20 $\min$. The wet cells were suspended in $30 \mathrm{~mL}$ of buffer A (50 $\mathrm{mM} \mathrm{NaH}_{2} \mathrm{PO}_{4}, 300 \mathrm{mM} \mathrm{NaCl}, 10 \mathrm{mM}$ imidazole, $\mathrm{pH}$ 8.0) and lysed in ultrasonic cell disruption system (JY92-2D) at a program: working for $5 \mathrm{~s}$ followed by a rest of $5 \mathrm{~s}, 20 \mathrm{~min}$ at 4 ${ }^{\circ} \mathrm{C}$. The lysate was centrifugated at 8000 r.p.m. for $30 \mathrm{~min}$. The supernatant was filtrated by $0.45 \mu \mathrm{m}$ disposable sterile filter, and then loaded onto Ni(II)-NTA column (Qiagen; $5 \mathrm{~mL}$ ) preequilibrated with buffer $\mathrm{A}$. The column was washed with 200 $\mathrm{mL}$ of buffer B (50 mM NaH $\mathrm{PO}_{4}, 300 \mathrm{mM} \mathrm{NaCl}, 20 \mathrm{mM}$ imidazole, $\mathrm{pH}$ 8.0) and finally eluted with $5 \mathrm{~mL}$ of buffer $\mathrm{C}$ (50 $\mathrm{mM} \mathrm{NaH} \mathrm{PO}_{4}, 300 \mathrm{mM} \mathrm{NaCl}, 250 \mathrm{mM}$ imidazole, $\mathrm{pH}$ 8.0). The eluate bearing purified MaArsM protein was removed to a $10-\mathrm{kDa}$ ultrafiltration centrifuge tube (Sartorius) and concentrated by centrifugation at 8000 r.p.m. for 1 h. Finally, the buffer $\mathrm{C}$ bearing MaArsM protein was exchanged into MOPS buffer (50 mM MOPS, 150 mM KCl, pH 7.4) using Micro BioSpin Chromatography Column (Bio-Rad). MaArsM protein was identified by sodium-dodecyl-sulfate polyacrylamide gel electrophoresis (SDS-PAGE), and determined its concentration by the method of Bradford (Bio-Rad Protein Assay), ${ }^{27}$ using BSA (Sigma) as a standard. 
Arsenic methylation in vitro was performed in MOPS buffer containing MaArsM protein, glutathione (GSH), SAM, and As(III). The As species during the reaction process was monitored at the different time $(0.5,1.5,3,4.5,6,20 \mathrm{~h})$. In some cases, a series of concentrations of MaArsM protein, GSH, SAM, or As(III) were used in corresponding assays. Different kinds of thiol compounds in SI Table S1 were used and analyzed their effects on the enzymatic methylation of As(III). The reactions were terminated by boiling for $5 \mathrm{~min}$, oxidized by $10 \%(\mathrm{v} / \mathrm{v}) \mathrm{H}_{2} \mathrm{O}_{2}$ overnight, finally filtered by 0.45 $\mu \mathrm{m}$ filters and analyzed As species by HPLC-ICP-MS.

Preparation of MaArsM Mutants. A certain cysteine (Cys) of MaArsM was substituted for serine, through overlapping extension PCR with plasmid pET28a+arsM as DNA template. The primers used for site-directed mutagenesis are listed in SI Table S2. PCR products were double-digested by EcoRI and XhoI, and cloned into the EcoRI/XhoI-digested pET28a+ vector. The plasmids containing MaarsM mutants were sequenced to ensure that no errors had been introduced during amplification. The plasmid vectors carrying different MaarsM mutants were transformed into E. coli BL21(DE3), respectively. Protein purification and concentration determination were performed as described above. Seven mutants of MaArsM (C24/25S, C30S, C31S, C62S, C150S, C194S, and C200S) were established.

Arsenic Speciation Analysis. Arsenic speciation was analyzed by HPLC-ICP-MS (Agilent 1200 series and Agilent 7500 series, Agilent Technologies, U.S.A.) as described. ${ }^{28}$ An anion-exchange column (PRP-X100, Hamilton Company, U.S.A.) was used and consisted of a precolumn $(11.2 \mathrm{~mm}$; $12-20 \mu \mathrm{m})$ and a PRP-X100 $10-\mu \mathrm{m}$ anion-exchange column $\left(250 \times 4.1 \mathrm{~mm}^{2}\right)$. The mobile phase consisted of $10 \mathrm{mM}$ diammonium hydrogen phosphate $\left[\left(\mathrm{NH}_{4}\right)_{2} \mathrm{HPO}_{4}\right]$ and $10 \mathrm{mM}$ ammonium nitrate $\left[\mathrm{NH}_{4} \mathrm{NO}_{3}\right]$, adjusted to $\mathrm{pH} 6.2$ with nitric acid. The mobile phase was pumped through the column at a flow rate of $1.0 \mathrm{~mL} \mathrm{~min}{ }^{-1}$.

\section{RESULTS}

Arsenic Methylation by Methanoarchaea. Under anaerobic conditions, $M$. acetivora $\mathrm{C} 2 \mathrm{~A}$ had the capacity of methylating As, as monomethylarsenic (MMAs) was detected in the medium containing As(III) (Figure 1). About 10\% of the total As was transformed into MMAs in the medium containing $10 \mu \mathrm{M}$ As(III), and $13 \%$ in that with $5 \mu \mathrm{M}$ As(III) (SI Figure S1). In addition, MMAs was detected in the medium added with $\operatorname{As}(\mathrm{V})$, but less than that in the medium with As(III). There was no methylated As in the control (no bacterial inoculation).

Cloning of the arsM Gene. PCR cloning using the total DNA extracts of $M$. acetivora $C 2 A$ yielded a putative ars $M$ gene (750 bp), designated as MaarsM (NCBI Reference Sequence: NP_618654.1). MaarsM gene encoded the MaArsM protein of 249 residues, with a predicted molecular mass of $26.67 \mathrm{kDa}$. Sequence homology analysis showed that MaArsM had high similarity with the ArsM of Rhodopseudomonas palustris (43\% identity and $75 \%$ similarity). ${ }^{29}$ With the ArsMs from a series of cyanobacterial species, ${ }^{7}$ MaArsM shared lower similarity (average 23\% identity and 51\% similarity). In addition, MaArsM also exhibited significant, but low similarity to mammalian AS3MT methyltransferase (21\% identity and 50\% similarity), ${ }^{5}$ and to the ArsM of eukaryotic alga Cyanidioschyzon sp. isolate 5508 ( $21 \%$ identity and $45 \%$ similarity). ${ }^{6}$

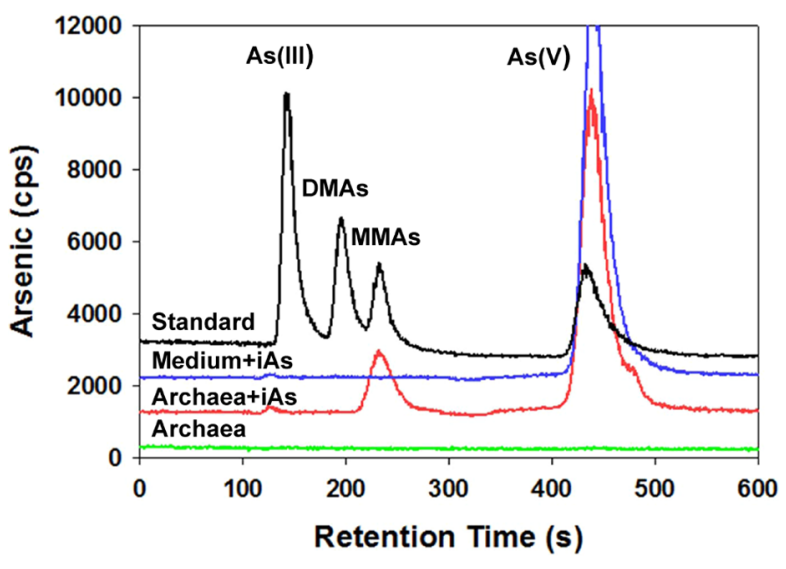

Figure 1. Arsenic transformation by $M$. acetivorans C2A. Archaea C2A were cultured in the presence of $5 \mu \mathrm{M}$ As(III) for 20 days. The medium without inoculation or As addition was controls. The As species in the medium were analyzed as described in "Materials and Methods".

MaArsM Enzyme Detoxified As(III) in Vivo. To elucidate the function of MaArsM in vivo, MaarsM gene was expressed in As-sensitive E. coli AW3110 ( $\triangle \operatorname{arsRBC})$, which had no orthologous arsM gene. Expression of MaarsM clearly conferred the As(III) resistance to E. coli. Cells expressing MaarsM gene grew much better than that bearing vector plasmid pET28a+ when exposed to $50 \mu \mathrm{M}$ As(III) (Figure 2A). Furthermore, expression of MaarsM allowed the cellular growth at $\mathrm{As}$ (III) concentration as high as $100 \mu \mathrm{M}$ while that of plasmid pET28a+ failed to do that (Figure 2A).

As(III) Methylation and Volatilization by $E$. coli AW3110 Expressing MaarsM. In the presence of As(III), dimethylarsenic (DMAs) were detected in the medium inoculated with E. coli AW3110 expressing MaarsM gene (Figure 2B), while no methylated As was detectable in the medium of E. coli with vector plasmid pET28a+. This result indicated that the MaArsM enzyme encoded by MaarsM gene indeed catalyzed As(III) methylation. At $10 \mu \mathrm{M}$ As(III) concentration, transgenic E. coli methylated $94 \%$ of the total As in the medium into DMAs.

E. coli AW3110 expressing MaarsM gene effectively volatilized As when exposed to different concentrations of As(III). The gaseous products were mainly trimethylarsine (TMAs) which was oxidized and identified as trimethylarsine oxide (TMAO), together with small amount of dimethylarsine $(\mathrm{DMAsH})$ detectable as oxidized dimethylarsenate [DMA(V)] (Figure $2 \mathrm{C}$ ). At 5 and $20 \mu \mathrm{M} \mathrm{As}$ (III), only $0.05 \%$ and $0.02 \%$ of the total As (about 25 and $44 \mathrm{ng}$ ) was volatilized from the medium grown with E. coli bearing MaarsM (SI Figure S2). At higher As(III) concentrations (50, $100 \mu \mathrm{M})$, E. coli with Maars $M$ volatilized about $0.2 \%$ and $0.4 \%$ of the total As (about 0.73 and $3.135 \mu \mathrm{g}$ ) from the medium, respectively (SI Figure S2). However, when As(III) concentration up to $200 \mu \mathrm{M}$, volatilization was much weaker and only $0.001 \%$ of total As (about $18 \mathrm{ng}$ ) was released, perhaps attributed to the As toxicity and poor growth of cells.

Methylation of As(III) by Purified ArsM Enzymes in Vitro. To gain a better insight into the mechanism of enzyme, a series of in vitro methylations were assayed with purified MaArsM protein (Figure 3). MMAs and TMAO were formed after $0.5 \mathrm{~h}$, with small amount of DMAs appearing at $1.5 \mathrm{~h}$ (Figure 3B). The concentrations of DMAs and MMAs 

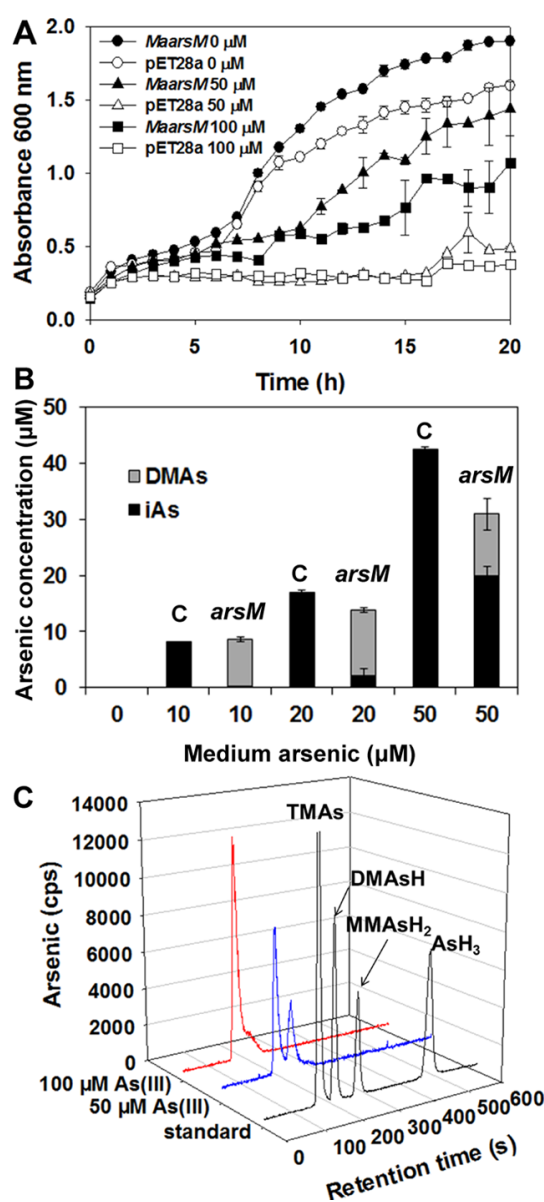

Figure 2. Arsenic resistance, methylation and volatilization by $E$. coli AW3110 ( $\triangle$ arsRBC) expressing pET28a+MaarsM. (A) The growth curves of E. coli bearing MaarsM or vector plasmid pET28a+. E. coli was cultured in $\mathrm{LB}$ medium containing the indicated concentrations of As(III), $50 \mu \mathrm{g} \mathrm{mL}^{-1}$ kanamycin and $0.3 \mathrm{mM}$ IPTG at $37^{\circ} \mathrm{C}$. Cellular growths were monitored as absorbance at $600 \mathrm{~nm}$ at the indicated time points. The error bars indicate the standard errors of three triplicates. (B) As(III) methylation by E. coli expressing MaarsM. E. coli was incubated in LB medium with the indicated concentrations of As(III) $(0,10,20$, and $50 \mu \mathrm{M}), 50 \mu \mathrm{g} \mathrm{mL}^{-1}$ kanamycin and $0.3 \mathrm{mM}$ IPTG at $37^{\circ} \mathrm{C}$ for $20 \mathrm{~h}$. The As species in the supernatants of cultures were analyzed by HPLC-ICP-MS as described in "Materials and Methods". C, E. coli bearing vector plasmid pET28a+ as control; arsM, E. coli bearing MaarsM. The error bars indicate the standard errors of three triplicates. (C) The species of volatile As released by E. coli expressing MaarsM. E. coli was grown in LB medium containing 50/100 $\mu \mathrm{M}$ As(III), $50 \mu \mathrm{g} \mathrm{mL}^{-1}$ kanamycin and $0.3 \mathrm{mM}$ IPTG at $37^{\circ} \mathrm{C}$ for $48 \mathrm{~h}$. Volatile As from medium was chemo-trapped as described in the Materials and Methods section, the species of which were analyzed by HPLC-ICP-MS

increased with the reaction time, concomitant with the decrease of inorganic As (Figure 3B). The quantity of TMAO decreased with time. At $20 \mathrm{~h}$, the amount of DMAs and MMAs exceeded that of inorganic As but TMAO disappeared (Figure 3B). As(III) methylation level by a series of protein concentrations was demonstrated (Figure 3C). Result showed that the production of methylated As was promoted by increasing MaArsM concentrations in the reaction solution. The account of MMAs decreased when MaArsM concentration exceeded 1 $\mu \mathrm{M}$. Overall, the total amount of methylated As kept on increasing, concomitant with the increase of MaArsM concentration within $10 \mu \mathrm{M}$.
The amount of methylated As increased with the rising As(III) concentrations in the reaction solution (Figure 3D), but the percentage of that indeed decreased. Almost $95 \%$ of the total As was transformed into methylated As when treated with $5 \mu \mathrm{M}$ As(III), while the percentage dropped to about $75 \%$ when with $20 \mu \mathrm{M}$ As(III).

Effects of SAM and GSH Concentrations on the Enzymatic Methylation of As(III). As(III) methylation did not occur in the absence of SAM or GSH (SI Figure S3). SAM served as a methyl donor while GSH as a thiol cofactor according to Hayakawa's pathway for As methylation. ${ }^{30} \mathrm{We}$ carried out As(III) methylation assays in the presence of a series of concentrations of SAM or GSH (SI Figure S3A). Results showed that the effect of SAM or GSH on the efficiency of methylation is a function of the concentration added. The level of methylated As went up with increasing GSH concentration, although MMAs declined when GSH concentration exceeding $10 \mathrm{mM}$ (SI Figure S3A). Therefore, As(III) methylation was promoted by increasing GSH concentration (within $20 \mathrm{mM}$ ). On the contrary, excessive SAM inhibited the enzymatic reaction. Maximal level of As(III) methylation occurred at $1 \mathrm{mM}$ SAM, over which the sum of methylated As began to decrease (SI Figure S3B).

Effect of Different Thiols on the Enzymatic Methylation of As(III). GSH is not produced by archaea, although it is a major thiol in many bacteria and nearly all eukaryotes. ${ }^{31}$ Coenzyme M (CoM; 2-mercaptoethanesulfonic acid) as an analog of $\mathrm{GSH}^{32}$ is almost only produced by methanoarchaea and plays roles in some thiol-associated processes, such as methanogenesis. For the As(III) methylation by MaArsM, $\mathrm{CoM}$ can act as a cofactor and is much more efficient than GSH (SI Figure S4). To further examine the effect of different thiol types on the enzymatic methylation, several other thiol compounds were demonstrated as the cofactors of MaArsM, respectively, and proved to be unequal in supporting As(III) methylation (Figure 4). Homocysteine was a relatively ideal cofactor. DMAs were the main methylated product, except in the cases of cysteine, thioglycolic acid, and 3-mercaptopropionic acid, in which MMAs was dominant product. In addition, some thiol compounds such as penicillamine, 2,3dimercaptopropanol (DMP) and 2,3-dimercaptosuccinic acid (DMSA), did not work for As(III) methylation by MaArsM at all (Figure 4).

Conserved Cysteine Residues Cys62, Cys150, and Cys200 of MaArsM. Cysteines in As(III) methyltransferases are especially important in catalyzing As methylation process, attributed to their thiol groups. ${ }^{33,34}$ The amino acid sequence of MaArsM contained eight cysteines, of which the individual function was assessed by site-directed mutagenesis. Cysteine pair or a single cysteine was substituted for serine(s), creating mutants C24/25S C30S, C31S, C62S, C150S, C194S, and C200S (SI Figure S5). Compared with normal MaArsM, $\mathrm{C} 150 \mathrm{~S}$, and C200S completely lost their activities of As(III) methylation, while the activity of C62S severely decreased (Figure 5A). Furthermore, MMAs was transformed into DMAs by C62S, as in the case of normal MaArsM, but not by C150S or C200S (Figure 5B). Two kinds of controls (without enzyme or arsenicals) were performed together with the experimental groups. No methylated As species appeared in controls. Results showed that three cysteines (Cys62, Cys150, and Cys200) played roles in first methylation step [from As(III) to MMAs], while two of which (Cys150 and Cys200) were required for second methylation step (form MMAs to DMAs) in 

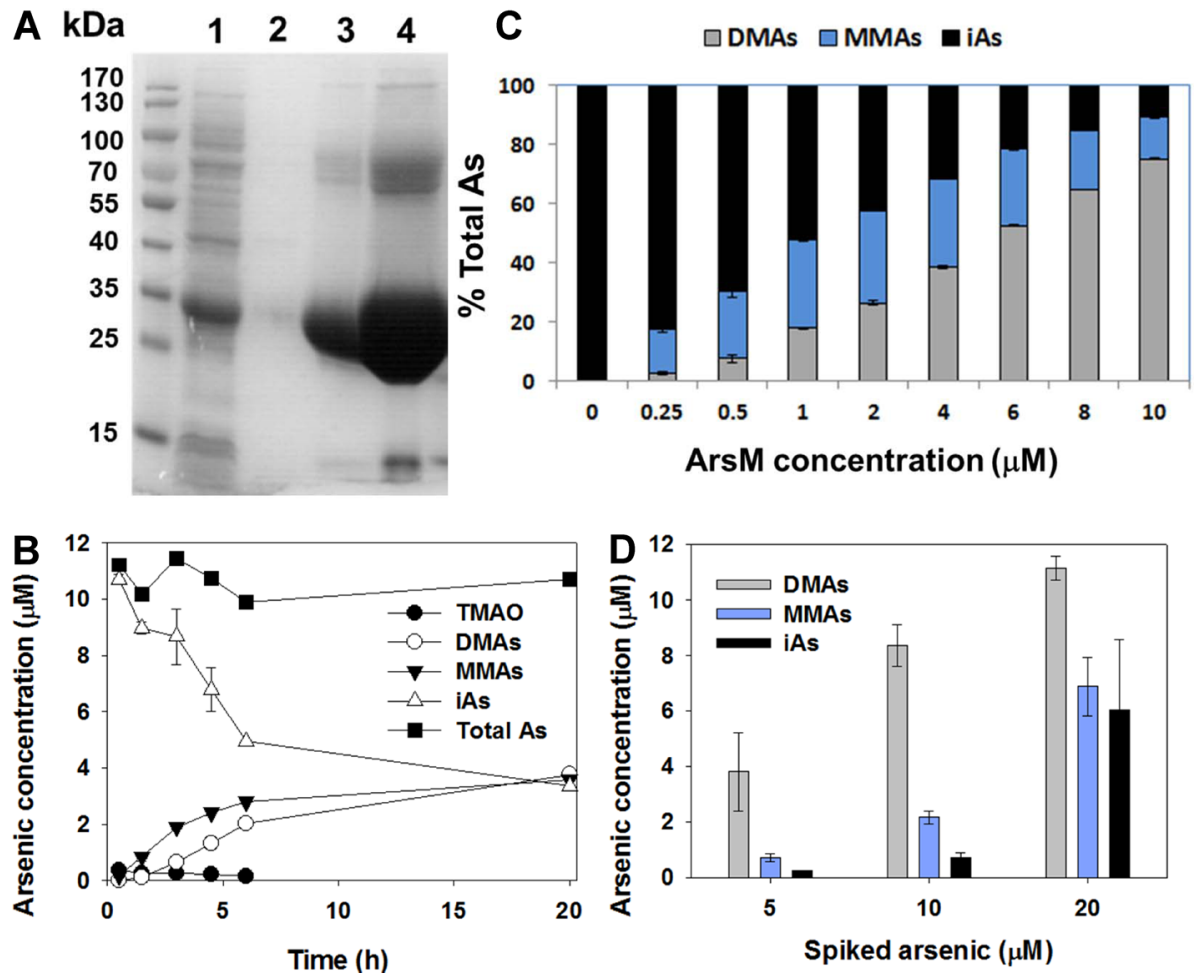

Figure 3. Purification and functional verification of MaArsM. (A) SDS-PAGE showing the purity of the purified MaArsM. Lane 1, cell lysis solution; Lane 2, collections of the washing buffer outflowing from Ni(II)-NTA column; Lane 3, the eluate outflowing from Ni(II)-NTA column; Lane 4, concentrated MaArsM solution. (B) Time dynamic of As(III) methylation by purified MaArsM enzyme. The reaction mixture contained $10 \mu \mathrm{M}$ As(III), $1 \mathrm{mM} \mathrm{SAM}, 8 \mathrm{mM} \mathrm{GSH}$, and $5 \mu \mathrm{M}$ pudified MaArsM in MOPS buffer at $37^{\circ} \mathrm{C}$. Arsenic species in reaction solution were analyzed at the indicated time points by HPLC-ICP-MS as described in the Materials and Methods section. (C) Methylation levels by different concentrations of MaArsM enzyme were tested in MOPS buffer containing $10 \mu \mathrm{M} \mathrm{As}(\mathrm{III}), 1 \mathrm{mM} \mathrm{SAM}$ and $8 \mathrm{mM} \mathrm{GSH}$ at $37{ }^{\circ} \mathrm{C}$ for $20 \mathrm{~h}$. (D) Methylation levels in different As(III) concentrations. The reaction mixture contained a certain concentration of As(III) (5, 10, and $20 \mu \mathrm{M}), 1 \mathrm{mM} \mathrm{SAM}, 8 \mathrm{mM}$ GSH, and $10 \mu \mathrm{M}$ pudified MaArsM in MOPS buffer, at $37^{\circ} \mathrm{C}$ for $20 \mathrm{~h}$. All error bars indicate the standard errors of three triplicates.

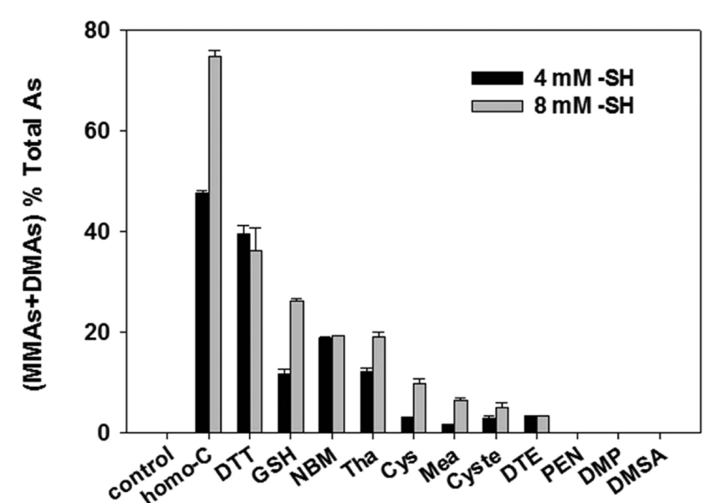

Figure 4. Methylation of $\mathrm{As}(\mathrm{III})$ as a function of different thiol cofactors. Methylation of As was tested in MOPS buffer containing 10 $\mu \mathrm{M}$ As(III), 4 or $8 \mathrm{mM}$ thiols, $1 \mathrm{mM}$ SAM and $5 \mu \mathrm{M}$ ArsM enzyme. The thiols used in the experiment are homo-C, L-homocysteine; DTT, Dithiothreitol; GSH, Glutathione; NBM, 3-Nitrobenzylmercaptan; Tha, Thioglycolic acid; Cys, Cysteine; Mea, 3-Mercaptopropionic acid; Cyste, Cysteamine; DTE, Dithioerythritol; PEN, Penicillamine; DMP, 2,3-Dimercaptopropanol; and DMSA, 2,3-Dimercaptosuccinic acid. The error bars indicate the standard errors of three triplicates.

Challenger's pathway. ${ }^{35}$ For the mutants C24/25S, C30S, C31S, or C194S, no significant difference was observed in enzymatic activity, compared with normal MaArsM (Figure 5C, 5D). We concluded that Cys24, Cys25, Cys30, Cys31, and Cys 194 were not involved in As methylation.

\section{DISCUSSION}

To our knowledge, MaArsM enzyme is the first identified and characterized As(III) methyltransferase from an archaeon. MaArsM enzyme provides some insights into the mechanism of As resistance in archaea. The expression of MaarsM gene conferred As resistance to As-hypersensitive E. coli, even at As(III) concentration as high as $100 \mu \mathrm{M}$. The E. coli bearing MaarsM gene could transform inorganic As into various methylated species. Given enough time and optimal conditions, almost all of the As(III) in medium can be methylated by $E$. coli, with DMAs as the dominant product. E. coli with MaarsM produced gaseous TMAs and $\mathrm{DMAsH}$, and the quantity can reach $3 \mu \mathrm{g}$ ( $0.4 \%$ of the total As). MaArsM enzyme may metabolize As(III) to a lower level permitting cellular growth in vivo, in other words, it may relieve As toxicity in cells, consistent with the idea that As methyltransferase has an important physiological role in detoxifying As.

Cysteine residues are especially important for As methylation and the most conserved as functional sites. ${ }^{36}$ For MaArsM enzyme, Cys62, Cys150, and Cys200 are shown to determine its function in As methylation. Sequence analysis showed that these cysteines are conserved in almost all the As(III) methyltransferases identified in members of every kingdom, from bacteria to humans. For the CmArsM from eukaryotic alga Cyanidioschyzon sp. isolate 5508, it is proposed that Cys174 and Cys224 of the enzyme play a central role in binding As(III) or MMA(III), while Cys72 is the last residue to participate in As(III) binding but is not involved in the binding 

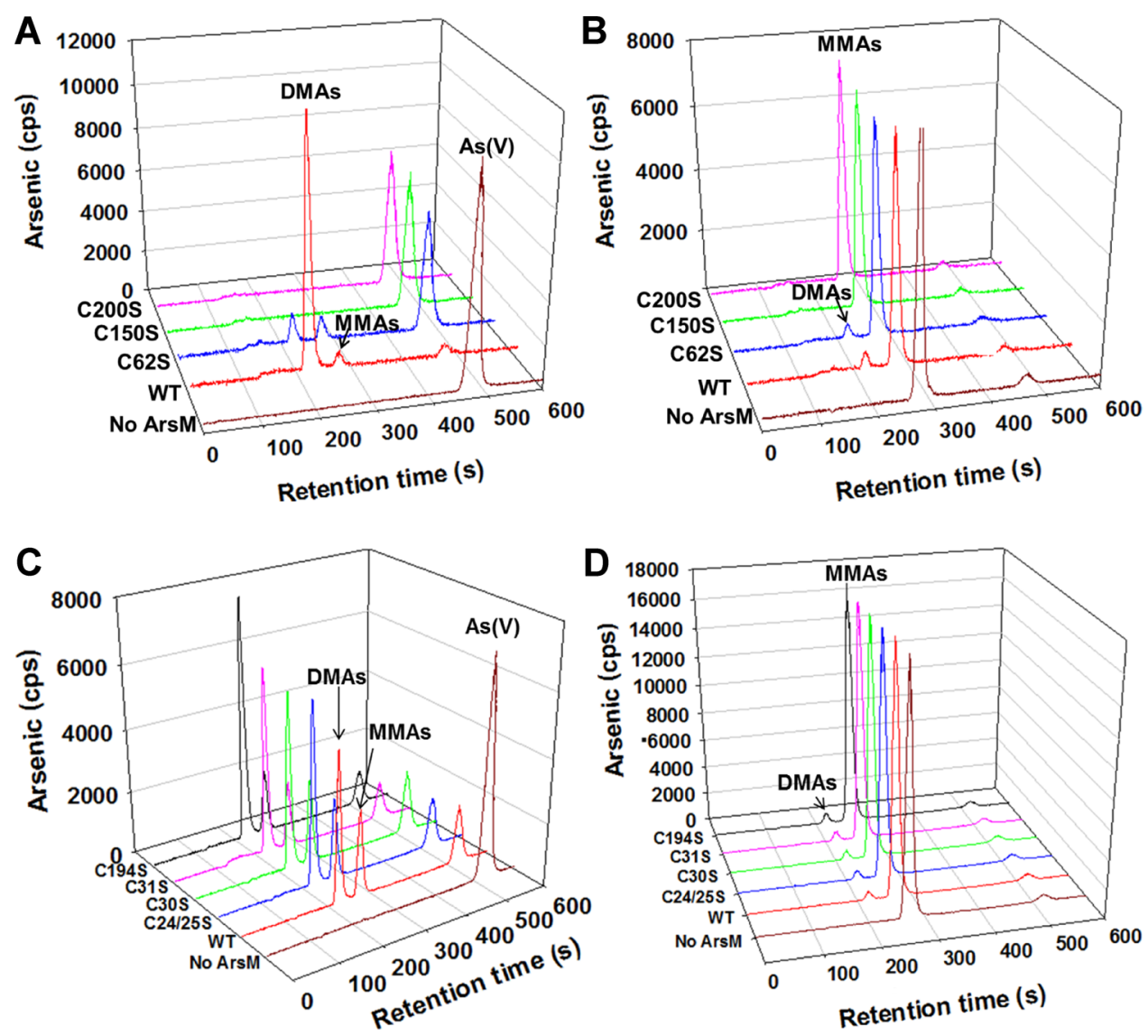

Figure 5. Methylation of As(III) or MMAs by normal or mutant MaArsM enzymes. Methylation of As was tested in MOPS buffer containing $10 \mu \mathrm{M}$ As(III) (A and C) or $10 \mu \mathrm{M}$ MMAs (B and D), $1 \mathrm{mM} \mathrm{SAM}, 8 \mathrm{mM} \mathrm{GSH}$, and $10 \mu \mathrm{M}$ ArsM enzyme. The reaction solutions were kept at $37^{\circ} \mathrm{C}$ for $20 \mathrm{~h}$ and analyzed As species by HPLC-ICP-MS.

of MMA(III) or DMA(III). ${ }^{34}$ For the mouse AS3MT, Cys 157 and Cys207 are speculated to form an intramolecular disulfide bond during As methylation reaction. ${ }^{37}$ In addition, Cys72, Cys156, and Cys206 of the human AS3MT are essential in maintaining hAS3MT structure. ${ }^{33}$ The As methylating gene may be horizontally transferred from prokaryote to eukaryote for an environmental adaptation. ${ }^{38,39}$ The characterization of ArsM from archaea, which are likely the oldest lives on the Earth, could be advantageous for studying the evolution of ArsMs.

The thiols play an important role in detoxification of toxic metals, including As methylation process, in which a thiol cofactor was required. Some intracellular or extracellular thiols have been shown different abilities to support As methylation. $\mathrm{CoM}$, an important coenzyme produced at millimolar concentration in methanogens, ${ }^{40}$ is more ideal for As methylation by MaArsM in comparison with GSH. Homocysteine, existing in archaea, bacteria, and eukarya and mediating As methylation by the one-carbon metabolism mechanism in mammals, ${ }^{41,42}$ also exhibited relatively high capability in As methylation by MaArsM. According to the Hayakawa's pathway for As methylation, the glutathionylated arsenicals are preferred substrates for the methylating enzymes. ${ }^{30}$ The effect of thiols on As methylation may critically depend on the characteristics of the As-thiol complex (such as geometry, stability, etc.). For example, dithiothreitol (DTT) usually forms an unstable complex with As(III), while DMSA and DMP usually form stable chelate structures with As(III). ${ }^{43}$ The complex of As-DTT is flexible enough to bind the methylating enzyme, however, that of As-DMSA or As-DMP fails to that. DTE forms a bicyclic dithiolate with As(III), while its stereoisomer DTT, as well as GSH, cysteine, form respective trithiolates with As(III). ${ }^{44,45}$ The trithiolate structure is preferable as substrate than the dithiolate in As(III) methylation. These may partly explain the different efficiency of thiols in methylation reaction. The thiols are ubiquitous in anoxic environments, ${ }^{46-50}$ and may be originated from the decomposition of residues or from in situ production by microorganisms, or both. The ambient low-molecular-weight thiols can mediate metal biochemistry, such as the uptake and methylation of mercury by anaerobic bacteria. ${ }^{51}$ The levels of As methylation and volatilization were enhanced by adding organic matter to soils, such as manure, cow dung, and dried distillers grain. $^{21,52,53}$ One possible explanation is that the concentrations of the thiols in soils were increased through the decomposition of organic matters ${ }^{54}$ and the uptake of thiols by soil microbes (such as archaea) improved As biomethylation.

Environmental Implications. Archaea are widespread in every environment that has been explored. ${ }^{55}$ In As-rich extreme environments, archaea including methanoarchaea, represent a considerable fraction of the prokaryotic world. ${ }^{56-58}$ It has been suggested that archaea play a considerable role in the biogeochemistry of metal(loid)s in the environment. ${ }^{59}$ Our results, showing the molecular mechanism of As methylation by $M$. acetivorans $\mathrm{C} 2 \mathrm{~A}$ could contribute to the understanding of archaeal role in As biogeochemistry in the environment. The potential applications of either archaeal biomass or archaeal enzymes in bioremediation is alsp possible. For example, the 
ability of methanoarchaea to thrive in anaerobic or other extreme environments suggests that they are ideally suited for use in the bioremediation of anoxic sludge or marine coastal sediment, etc. Archaeal enzymes mass-produced in wellcharacterized E. coli provide an outlook for developing genetic engineering bacteria aimed to remediate As-contaminated soil or water.

\section{ASSOCIATED CONTENT}

\section{S Supporting Information}

Figure S1: The percentage of As species formed in the medium of $M$. acetivorans C2A. Figure S2: Arsenic volatilization by $E$. coli AW3110 ( $\triangle \operatorname{arsRBC}$ ) expressing MaarsM. Figure S3: Methylation of As(III) as a function of substrate (GSH or SAM) concentrations. Figure S4: The percentage of As species formed in the enzymatic methylation of As(III) with CoM or GSH as cofactor. Figure S5: The graph of SDS-PAGE for purified normal and mutant MaArsM proteins. Table S1: The abbreviations and structures of thiol compounds investigated in MaArsM assays. Table S2: Primers used for the site-directed mutagenesis of enzyme MaArsM. This material is available free of charge via the Internet at http://pubs.acs.org/.

\section{AUTHOR INFORMATION}

\section{Corresponding Authors}

*Phone: +86-10-62-62936940; fax: +86-10-62936940; e-mail: ygzhu@rcees.ac.cn.

*Phone: +86-10-62-62936940; fax: +86-10-62936940; e-mail: gxsun@rcees.ac.cn.

\section{Notes}

The authors declare no competing financial interest.

\section{ACKNOWLEDGMENTS}

This project was financially supported by the State Key Program of Natural Science Foundation of China (No. 41330853), the Natural Science Foundation of China (No. 41371459), and the National High Technology Research and Development Program of China (863 Program, 2013AA06A209).

\section{REFERENCES}

(1) Mestrot, A.; Planer-Friedrich, B.; Feldmann, J. Biovolatilisation: A poorly studied pathway of the arsenic biogeochemical cycle. J. Environ. Monitor. 2013, 15, 1639-1651.

(2) Wang, P.; Sun, G.; Jia, Y.; Meharg, A. A.; Zhu, Y. A review on completing arsenic biogeochemical cycle: Microbial volatilization of arsines in environment. J. Environ. Sci. 2014, 26, 371-381.

(3) Thomas, F.; Diaz-Bone, R. A.; Wuerfel, O.; Huber, B.; Weidenbach, K.; Schmitz, R. A.; Hensel, R. Connection between multimetal(loid) methylation in methanoarchaea and central intermediates of methanogenesis. Appl. Environ. Microbiol. 2011, 77, 86698675.

(4) Wuerfel, O.; Thomas, F.; Schulte, M. S.; Hensel, R.; Diaz-Bone, R. A. Mechanism of multi-metal(loid) methylation and hydride generation by methylcobalamin and $\operatorname{cob}(\mathrm{I})$ alamin: A side reaction of methanogenesis. Appl. Organomet. Chem. 2012, 26, 94-101.

(5) Lin, S.; Shi, Q.; Nix, F. B.; Styblo, M.; Beck, M. A.; Herbin-Davis, K. M.; Hall, L. L.; Simeonsson, J. B.; Thomas, D. J. A novel $S$ adenosyl-L-methionine:arsenic(III) methyltransferase from rat liver cytosol. J. Biol. Chem. 2002, 277, 10795-10803.

(6) Qin, J.; Lehr, C. R.; Yuan, C.; Le, X. C.; McDermott, T. R.; Rosen, B. P. Biotransformation of arsenic by a Yellowstone thermoacidophilic eukaryotic alga. Proc. Natl. Acad. Sci., U. S. A. 2009, 106, 5213-5217.
(7) Yin, X. X.; Chen, J.; Qin, J.; Sun, G. X.; Rosen, B. P.; Zhu, Y. G. Biotransformation and volatilization of arsenic by three photosynthetic cyanobacteria. Plant Physiol. 2011, 156, 1631-1638.

(8) Ye, J.; Chang, Y.; Yan, Y.; Xiong, J.; Xue, X. M.; Yuan, D.; Sun, G. X.; Zhu, Y. G.; Miao, W. Identification and characterization of the arsenite methyltransferase from a protozoan. Aquat. Toxicol. 2014, 149, 50-57.

(9) Woese, C. R.; Kandler, O.; Wheelis, M. L. Towards a natural system of organisms: Proposal for the domains archaea, bacteria, and eucarya. Proc. Natl. Acad. Sci., U. S. A. 1990, 87, 4576-4579.

(10) Delong, E. F.; Wu, K. Y.; Prezelin, B. B.; Jovine, R. V. M High abundance of archaea in antarctic marine picoplankton. Nature 1994, 371, 695-697.

(11) Rothschild, L. J.; Mancinelli, R. L. Life in extreme environments. Nature 2001, 409, 1092-1101.

(12) Biddle, J. F.; Lipp, J. S.; Lever, M. A.; Lloyd, K. G.; Sorensen, K. B.; Anderson, R.; Fredricks, H. F.; Elvert, M.; Kelly, T. J.; Schrag, D. P.; Sogin, M. L.; Brenchley, J. E.; Teske, A.; House, C. H.; Hinrichs, K. U. Heterotrophic archaea dominate sedimentary subsurface ecosystems off Peru. Proc. Natl. Acad. Sci., U. S. A. 2006, 103, 3846-3851.

(13) Conrad, R.; Erkel, C.; Liesack, W. Rice cluster I methanogens, an important group of Archaea producing greenhouse gas in soil. Curr. Opin. Biotechnol. 2006, 17, 262-267.

(14) Ahmann, D.; Krumholz, L. R.; Hemond, H. F.; Lovley, D. R.; Morel, F. M. M. Microbial mobilization of arsenic from sediments of the Aberjona watershed. Environ. Sci. Technol. 1997, 31, 2923-2930.

(15) Oremland, R. S.; Kulp, T. R.; Blum, J. S.; Hoeft, S. E.; Baesman, S.; Miller, L. G.; Stolz, J. F. A microbial arsenic cycle in a salt-saturated, extreme environment. Science 2005, 308, 1305-1308.

(16) Meharg, A. A.; Rahman, M. M. Arsenic contamination of Bangladesh paddy field soils: Implications for rice contribution to arsenic consumption. Environ. Sci. Technol. 2003, 37, 229-234.

(17) Polizzotto, M. L.; Kocar, B. D.; Benner, S. G.; Sampson, M.; Fendorf, S. Near-surface wetland sediments as a source of arsenic release to ground water in Asia. Nature 2008, 454, 505-508.

(18) Frohne, T.; Rinklebe, J.; Diaz-Bone, R. A.; Laing, G. D. Controlled variation of redox conditions in a floodplain soil: impact on metal mobilization and biomethylation of arsenic and antimony. Geoderma 2011, 160, 414-424.

(19) Mestrot, A.; Uroic, M. K.; Plantevin, T.; Islam, M. R.; Krupp, E. M.; Feldmann, J.; Meharg, A. A. Quantitative and qualitative trapping of arsines deployed to assess loss of volatile arsenic from paddy soil. Environ. Sci. Technol. 2009, 43, 8270-8275.

(20) Mestrot, A.; Feldmann, J.; Krupp, E. M.; Hossain, M. S.; Roman-Ross, G.; Meharg, A. A. Field fluxes and speciation of arsines emanating from soils. Environ. Sci. Technol. 2011, 45, 1798-1804.

(21) Huang, H.; Jia, Y.; Sun, G. X.; Zhu, Y. G. Arsenic speciation and volatilization from flooded paddy soils amended with different organic matters. Environ. Sci. Technol. 2012, 46, 2163-2168.

(22) Jia, Y.; Huang, H.; Sun, G. X.; Zhao, F. J.; Zhu, Y. G. Pathways and relative contributions to arsenic volatilization from rice plants and paddy soil. Environ. Sci. Technol. 2012, 46, 8090-8096.

(23) Vriens, B.; Lenz, M.; Charlet, L.; Berg, M.; Winkel, L. H. E. Natural wetland emissions of methylated trace elements. Nat. Commun. 2014, 5 (3035), 1-8, DOI: 10.1038/ncomms4035.

(24) Michalke, K.; Wickenheiser, E. B.; Mehring, M.; Hirner, A. V.; Hensel, R. Production of volatile derivates of metal(loid)s by microflora involved in anaerobic digestion of sewage sludge. Appl. Environ. Microbiol. 2000, 66, 2791-2796.

(25) Meyer, J.; Michalke, K.; Kouril, T.; Hensel, R. Volatilisation of metals and metalloids: an inherent feature of methanoarchaea? Syst. Appl. Microbiol. 2008, 31, 81-87.

(26) Galagan, J. E.; Nusbaum, C.; Roy, A.; Endrizzi, M. G.; Macdonald, P.; FitzHugh, W.; Calvo, S.; Engels, R.; Smirnov, S.; Atnoor, D.; Brown, A.; Allen, N.; Naylor, J.; Stange-Thomann, N.; DeArellano, K.; Johnson, R.; Linton, L. The genome of M. acetivorans reveals extensive metabolic and physiological diversity. Genome Res. 2002, 12, 532-542. 
(27) Bradford, M. M. A rapid and sensitive method for the quantitation of microgram quantities of protein utilizing the principle of protein-dye binding. Anal. Biochem. 1976, 72, 248-254.

(28) Zhu, Y. G.; Sun, G. X.; Lei, M.; Teng, M.; Liu, Y. X.; Chen, N. C.; Wang, L. H.; Carey, A. M.; Deacon, C.; Raab, A.; Meharg, A. A.; Williams, P. N. High percentage inorganic arsenic content of mining impacted and nonimpacted Chinese rice. Environ. Sci. Technol. 2008, 42, 5008-5013.

(29) Qin, J.; Rosen, B. P.; Zhang, Y.; Wang, G.; Franke, S.; Rensing, C. Arsenic detoxification and evolution of trimethylarsine gas by a microbial arsenite $S$-adenosylmethionine methyltransferase. Proc. Natl. Acad. Sci., U. S. A. 2006, 103, 2075-2080.

(30) Hayakawa, T.; Kobayashi, Y.; Cui, X.; Hirano, S. A new metabolic pathway of arsenite: arsenic-glutathione complexes are substrates for human arsenic methyltransferase Cyt19. Arch. Toxicol. 2005, 79, 183-191.

(31) Fahey, R. C. Novel thiols of prokaryotes. Annu. Rev. Microbiol. 2001, 55, 333-356.

(32) Fahey, R. C. Glutathione analogs in prokaryotes. B. B. A. Gen. Subjects 2013, 1830, 3182-3198.

(33) Song, X.; Geng, Z.; Li, X.; Zhao, Q.; Hu, X.; Zhang, X.; Wang, Z. Functional and structural evaluation of cysteine residues in the human arsenic $(+3$ oxidation state) methyltransferase (hAS3MT). Biochimie 2011, 93, 369-375.

(34) Marapakala, K.; Qin, J.; Rosen, B. P. Identification of catalytic residues in the $\mathrm{As}(\mathrm{III}) \mathrm{S}$-adenosylmethionine methyltransferase. Biochemistry 2012, 51, 944-951.

(35) Challenger, F. Biological methylation. Chem. Rev. 1945, 36, 315-361.

(36) Fomenko, D. E.; Marino, S. M.; Gladyshev, V. N. Functional diversity of cysteine residues in proteins and unique features of catalytic redox-active cysteines in thiol oxidoreductases. Mol. Cells 2008, 26, 228-235.

(37) Fomenko, D. E.; Xing, W.; Adair, B. M.; Thomas, D. J.; Gladyshev, V. N. High-throughput identification of catalytic redoxactive cysteine residues. Science 2007, 315, 387-389.

(38) Keeling, P. J.; Palmer, J. D. Horizontal gene transfer in eukaryotic evolution. Nat. Rev. Genet. 2008, 9, 605-618, DOI: $10.1038 / \mathrm{nrg} 2386$.

(39) Schönknecht, G.; Chen, W. H.; Ternes, C. M.; Barbier, G. G.; Shrestha, R. P.; Stanke, M.; Bräutigam, A.; Baker, B. J.; Banfield, J. F.; Garavito, R. M.; Carr, K.; Wilkerson, C.; Rensing, S. A.; Gagneul, D.; Dickenson, N. E.; Oesterhelt, C.; Lercher, M. J.; Weber, A. P. M. Gene transfer from bacteria and archaea facilitated evolution of an extremophilic eukaryote. Science 2013, 339, 1207-1210, DOI: $10.1126 /$ science.1231707.

(40) Balch, W. E.; Wolfe, R. S. Specificity and biological distribution of coenzyme M (2-mercaptoethanesulfonic acid). J. Bacteriol. 1979, $137,256-263$.

(41) De Kimpe, J.; Cornelis, R.; Vanholder, R. In vitro methylation of arsenite by rabbit liver cytosol: Effect of metal ions, metal chelating agents, methyltransferase inhibitors and uremic toxins. Drug Chem. Toxicol. 1999, 22 (4), 613-628.

(42) White, R. H. The biosynthesis of cysteine and homocysteine in Methanococcus jannaschii. B. B. A. Gen. Subjects 2003, 1624, 46-53, DOI: 10.1016/j.bbagen.2003.09.005.

(43) Spuches, A. M.; Kruszyna, H. G.; Rich, A. M.; Wilcox, D. E. Thermodynamics of the As(III)-thiol interaction: arsenite and monomethylarsenite complexes with glutathione, dihydrolipoic acid, and other thiol ligands. Inorg. Chem. 2005, 44, 2964-2972.

(44) Kolozsi, A.; Lakatos, A.; Galbács, G.; Madsen, A. Ø.; Larsen, E.; Gyurcsik, B. A pH-Metric, UV, NMR, and X-ray crystallographic study on arsenous acid reacting with dithioerythritol. Inorg. Chem. 2008, 47, $3832-3840$.

(45) Ioannou, P. V.; Tsivgoulis, G. M. Preparation of thiolates of arsenic(III) and bismuth(III) with dithioerythritol, 2-mercaptoethanesulfonic acid and its sodium salt, 6-mercaptopurine and its riboside. Main Group Chem. 2012, 11, 89-102.
(46) Kiene, R. P.; Taylor, B. F. Demethylation of dimethylsulfoniopropionate and production of thiols in anoxic marine-sediments. Appl. Environ. Microbiol. 1988, 54, 2208-2212.

(47) Matrai, P. A.; Vetter, R. D. Particulate thiols in coastal waters: The effect of light and nutrients on their planktonic production. Limnol. Oceanogr. 1988, 33, 624-631.

(48) Tang, D.; Hung, C. C.; Warnken, K. W.; Santschi, P. H. The distribution of biogenic thiols in surface waters of Galveston Bay. Limnol. Oceanogr. 2000, 45, 1289-1297.

(49) Al-Farawati, R.; Van Den Berg, C. M. G. Thiols in coastal waters of the western North Sea and English Channel. Environ. Sci. Technol. 2001, 35, 1902-1911.

(50) Zhang, J.; Wang, F. Thiols in wetland interstitial waters and their role in mercury and methylmercury speciation. Limnol. Oceanogr. 2004, 49, 2276-2286.

(51) Schaefer, J. K.; Morel, F. M. M. High methylation rates of mercury bound to cysteine by Geobacter sulfurreducens. Nat. Geosci. 2009, 2, 123-126.

(52) Edvantoro, B. B.; Naidu, R.; Megharaj, M.; Merrington, G.; Singleton, I. Microbial formation of volatile arsenic in cattle dip site soils contaminated with arsenic and DDT. Appl. Soil Ecol. 2004, 25 (3), 207-217.

(53) Mohapatra, D.; Mishra, D.; Chaudhury, G. R.; Das, R. P. Removal of arsenic from arsenic rich sludge by volatilization using anaerobic microorganisms treated with cow dung. Soil Sediment Contam. 2008, 17 (3), 301-311.

(54) Kiene, R. P.; Malloy, K. D.; Taylor, B. F. Sulfur-containing amino acids as precursors of thiols in anoxic coastal sediments. Appl. Environ. Microbiol. 1990, 56 (1), 156-161.

(55) Chaban, B.; Ng, S. Y. M.; Jarrell, K. F. Archaeal habitats-from the extreme to the ordinary. Can. J. Microbiol. 2006, 52, 73-116.

(56) Akerman, N. H.; Meyer-Dombard, D. R; Osburn, M. R; Amend, J. P. Archaeal communities in an arsenic-rich shallow-sea hydrothermal system. American Geophysical Union, Fall Meeting 2006, abstract \#B11B-1028.

(57) Bruneel, O.; Pascault, N.; Egal, M.; Bancon-Montigny, C.; GoniUrriza, M. S.; Elbaz-Poulichet, F.; Personne, J. C.; Duran, R. Archaeal diversity in a $\mathrm{Fe}-$ As rich acid mine drainage at Carnoules (France). Extremophiles 2008, 12, 563-571.

(58) Price, R. E.; Lesniewski, R.; Nitzsche, K. S.; Meyerdierks, A.; Saltikov, C.; Pichler, T.; Amend, J. P. Archaeal and bacterial diversity in an arsenic-rich shallow-sea hydrothermal system undergoing phase separation. Front. Microbiol. 2013, 4 (158), 1-19.

(59) Bini, E. Archaeal transformation of metals in the environment. FEMS Microbiol. Ecol. 2010, 73, 1-16. 